\title{
Past and Future Trends on the Effects of Occupant Behaviour on Building Energy Consumption
}

\section{Mahsa Torabi, Mohammadjavad Mahdavinejad*}

High-performance Architecture Laboratory, Department of Architecture, Tarbiat Modares University, Tehran, Iran

${ }^{*}$ Corresponding author: Mahdavinejad@modares.ac.ir

\section{$\Gamma$}

Crossef http://dx.doi.org/10.5755/j01.sace.29.2.28576

In recent decades, the need for an accurate evaluation of energy use in buildings has become increasingly growing due to the rise in environmental awareness and political pressure around the world. The estimation of energy consumption is, therefore, a crucial criterion during building early-stage design. This paper investigates the recent trends and achievements in modelling occupant behaviour in energy simulation studies and aims to highlight achievements and research gaps in the domain. This study presents a state-of-the-art theoretical review of the research background through published papers in leading journals within this research domain. The main goals of this study lay in the two layers of determining recent research trends and crucial findings in the subject of occupants' behaviour and energy consumption, and more importantly, to identify research gaps for future studies. This research review highlights several areas for future research including studying behaviour in different countries considering various climate, cultures and comfort preferences affecting energy-driven behaviour and conducting similar studies in different building typologies and occupancies. Moreover, based on the reviewed article, it is clear that evaluating occupant behaviour as an independent variable on a larger scale energy analysis in urban studies needs to be addressed in future studies. The authors found a lack of comprehensive approaches to comfort and considering all forms of comfort while studying behaviour and consumption in recent studies. It is recommended that further investigation of behaviour and total energy consumption regarding occupant real comfort conditions be conducted.

Keywords: building energy consumption, occupant behaviour, thermal comfort, energy efficient architecture, consumption prediction.

The building sector is the largest energy-consuming sector, accounting for $40 \%$ of the final energy consumption globally and an equally important source of carbon emissions. It also declares in less developed regions, energy use in buildings represents as much as $80 \%$ of the total energy use (Delzendeh, Wu, Lee, \& Zhou, 2017). Thus, predicting energy consumption is becoming more important in the design and construction of buildings, from the early design stages to the post-occupancy and demolish phase in building life cycle (Bemanian \& Torabi, 2019). Energy consumption in buildings is related to various factors including construction details, material specifications, climate, location, passive and active design strategies, the quality of the installed HVAC (Heating, ventilation, and air condition) system, maintenance, and occupant's interaction with the building (Becchio, Bello, Corgnati, \& Ingaramo, 2016; Song, Zhou, Zhang, Zheng, \& Yan, 2017). The relation

\section{Introduction}

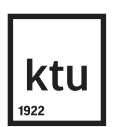

Journal of Sustainable Architecture and Civil Engineering Vol. 2 / No. 29 / 2021 pp. 83-101 DOI 10.5755/j01.sace.29.2.28576 
and interaction of these elements in a building are morphed in the early stages of design, which implicate the importance of evaluation and assessment in this phase. The utilization of simulation tools and running energy consumption studies in the design process help architects estimate the energy demand of the initial design and give them the chance to alter the design in order to enhance efficiency. Therefore, the accuracy of the energy simulation study is of great importance because not only it can change the architectural design output but also it can guide the whole design toward fulfilling sustainable and environmental-driven aims.

Although the current trend of building design has benefited a lot from energy calculating assistant tools, several studies in recent years showed that there is a remarkable difference between the predicted and actual energy consumption of buildings which needs more investigation (Kim et al., 2017; Ouf, Issa, \& Merkel, 2016; Pellegrino, Simonetti, \& Chiesa, 2016; Virote \& Neves-Silva, 2012). Cali et al. reported that the actual consumption amount is sometimes up to 3 times greater than the estimated amount in design (Z. Yu, Li, Li, Han, \& Zhang, 2015). The result of a similar study by Norfor et al. represents a more than $50 \%$ increase in actual energy consumption. In their study, researchers measured the actual annual energy consumption of a three-story office building located in Newjersey. The annual consumption was $325 \mathrm{kWh} / \mathrm{m} 2$, which is over twice the predicted value of $125 \mathrm{kWh} / \mathrm{m} 2$. Researchers introduced several reasons as a cause of this gap, for instance, this performance gap can be due to the difference between the building design and the as-built or this might be the result of equipment and material specifications (Norford, Socolow, Hsieh, \& Spadaro, 1994). Besides the mentioned factors, another influential factor in real energy consumption is building occupants by the means of their presence and thermal behaviour which forms their interactions with the buildings. Occupant interaction with the building can vary a lot including opening windows and blinds, use of HVAC systems, changes in setpoints due to thermal preference, maintenance and equipment efficiency, use of equipment and lightings, using hot water, etc (Delzendeh et al., 2017; Gilani, Brien, Gilani, \& Brien, 2017). Occupants and their thermal behaviour are taken into account in simulation studies but recent studies have revealed that this factor has a great direct influence on total consumption and is more complex and dynamic than was assumed till now (Becchio et al., 2016; Kim et al., 2017; Leroy \& Yannou, 2018).

Nevertheless, real-time energy use evaluation has been studied in numerous research projects. For example, in a study by Yun et al. on two identical flats within the same building block, the analysis demonstrated a significant difference between the total energy consumption. Researchers introduced differences in occupancy levels and duration and variations in the occupants' thermal preferences as the key reasons for different total energy use which highlights the pivotal role of occupants in energy consumption and building environmental footprint (Yun, Choi, \& Kim, 2014).

A study on the energy consumption of six commercial buildings in South Africa (with hot and dry climates) reported that $56 \%$ of the actual energy consumption was consumed during nonworking hours, which in simulation studies was not considered. To be more detailed, the reason for this remarkable gap is that occupant behaviour was not modeled in primary energy studies based on reality. In this case, researchers determined that occupants failed to turn off the HVAC system and lights before vacating the building, which results in doubling the total consumption (Alam, Bao, Zou, \& Sanjayan, 2017).

In another study, Martinaitis and Zavadskas conducted five different studies to evaluate the efficiency of the current simulation tool, even with accurate models. Researchers concluded that human behaviour and occupant preferences were the main two reasons for the observed gap between prediction and real-time energy consumption (S. Wang, Kim, \& Johnson, 2017).

Despite active research being undertaken in this area, the findings are still sparse and fragmented and, therefore, there is a real need for international collaboration in the sharing of collected data and discovered findings. This paper aims to conduct a comprehensive review of existing studies 
in a specific domain, to discover the effectiveness of occupant behaviour on energy consumption and environmental footprint in residential buildings. This study aims to identify the latest research trends, point out major findings achieved and facilitate future works and projects to fill the gaps in the edge of knowledge.

\section{Sampling}

Review papers usually start with a process of 'search' for relevant articles, using citation indexes against predetermined criteria for eligibility to provide a list of papers relating to the research area. To reduce bias, a clear approach for research was adopted, including both quantitative and qualitative analysis as well as reviews and technical notes. Therefore, Science Direct as the leading citation index organization was used. For this study, the terms "building energy" and "occupant" were used to select any paper where it was found in the title, abstract, and or keywords. To limit this wide scope with more than a thousand papers and to focus closely on the influence of behaviour on building energy consumption, another search was made through the database using more relevant keywords. As a result, both "occupant behaviour" and "energy consumption" have been repeatedly used in the title and keywords. Following this selection process, a search up to 2019 identified more than 44 research papers for this review.

\section{Publication Date}

The selected papers for review were published between 1994 till 2019 with ascending trends. The majority of papers were published between 2011 and 2020, although early examples of such studies were published in the 1990s. The ascending trend in publication through

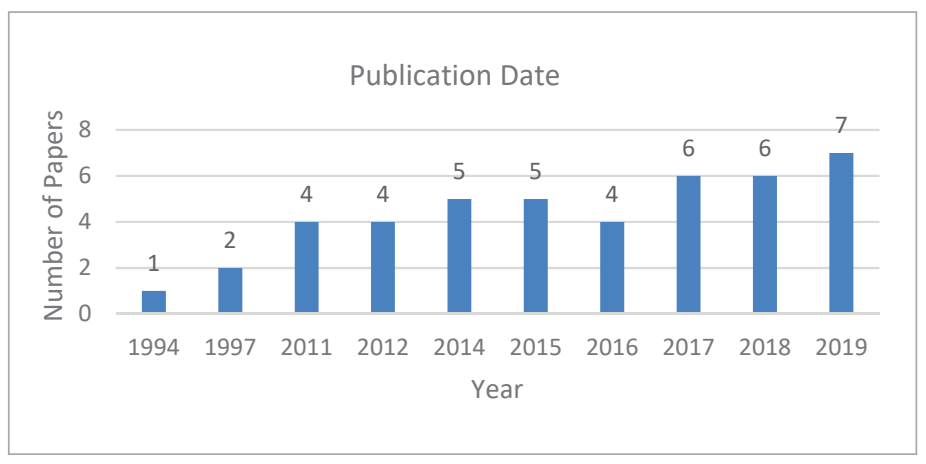
the 1990s and 2010s is observed in Fig. 1; however, the number of publications falls around the 2000s. To fill that gap, the authors added a qualitative research method to find hot topics for this gap time and to validate the findings of the review study. This was conducted using the opinion of experts and researchers of energy conservation, which will be thoroughly discussed in the following "discussion" sections.

\section{Leading Countries in the Field}

Fig. 2 demonstrates the scheme of the most active countries in this field. The radius of the circle shows the number of published papers while the colour indicates GDP (Gross Domestic Product) in 2020_as one of the criteria for economic developments of the country. The data used in this section is based on the affiliation of the corresponding author who is responsible for the project and academic contacts about the research.

Based on reviewed papers in this study, the United States and the Republic of China are the leading countries in this field, followed by respectively Republic of Korea, Canada and Netherlands, along with the UK, with the most published papers in this field in the studied period. European researchers are also active in this research area in contrast to researchers from developing countries in Central Asia, the Middle East, and also Africa with no studies on the list. It can be concluded from the data that the most active countries in the field, are also among the countries with the world's highest economic level while less active countries are mainly from developing economies. The exceptions are recently growing economies (Such as Brazil, India and Saudi Arabia) with high GDP and limited or no contribution to the research. It is anticipated to have researchers from these countries to investigate occupant's behavioural impact or pattern on their building sector in following years.

\section{Material and Method}

Fig. 1

Number of related papers by publication date 
While Fig. 2 shows the leading countries in this field of research, Fig. 3 shows the distribution of nations whose thermal behaviour has been studied. These pictures show some similarities and analogies. A similar pattern in both pictures shows that researchers are more inclined to research their own countries, such as USA, Canada, China and European Union. This is rational since most of the papers are derived from funded projects aiming to qualify the impact of the study on their stakeholders. The graph also shows that the academic community has neglected some parts of the world, as a result, a vast region is observed with almost no research to address occupants' energy-driven behaviour.

Fig. 2

Geographic distribution of active countries

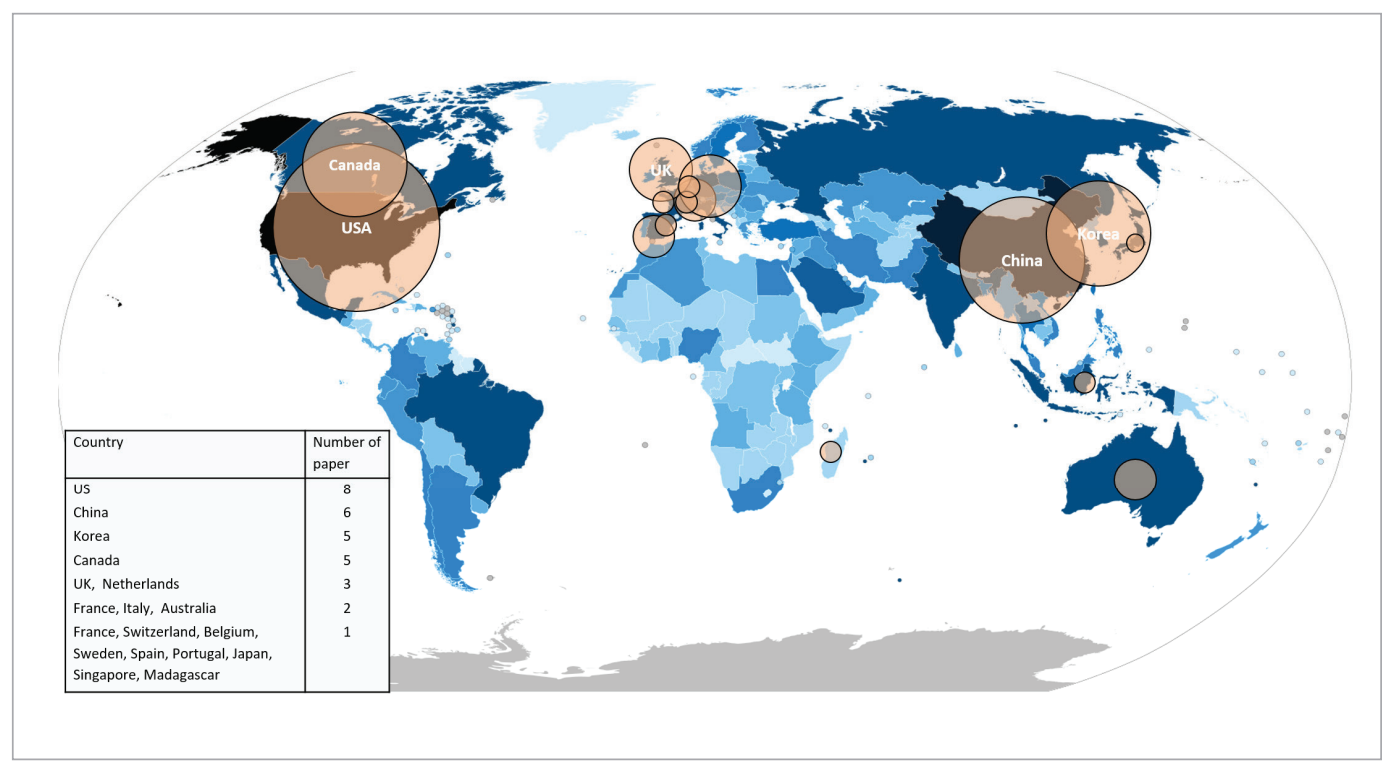

Fig. 3

Frequency and Geographical Distribution of Investigated Cases

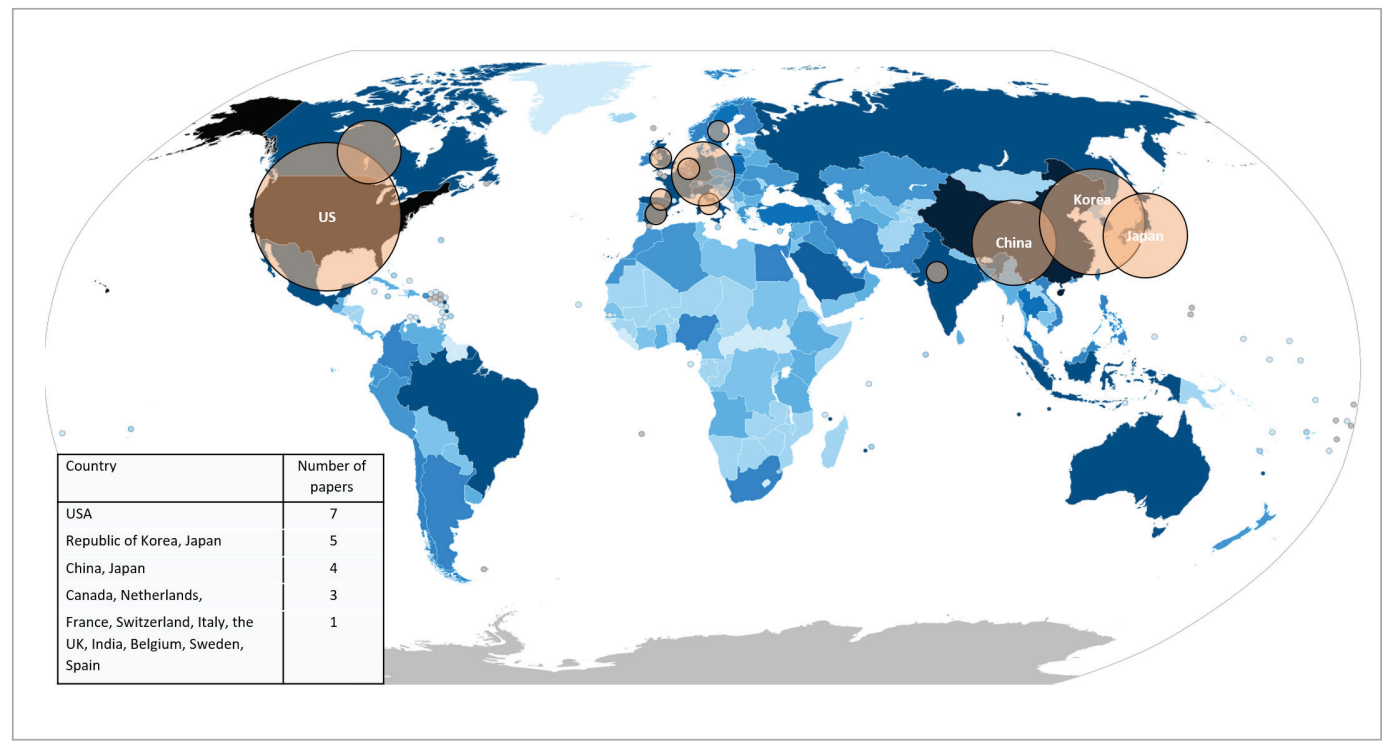

The geographical distribution of published papers shows the necessity of conducting similar researches in less regarded regions that have consumed more than $25 \%$ of total global primary consumption in 2017. this region includes Africa, Central Asia, the Middle East, and South America (Feng, Yan, \& Wang, 2016). 
It is important to bear in mind that occupant behaviour is a dependent variable that is known to be affected by cultural, geographical and climatic variables; therefore, to study the effect of this variable on energy consumption, researchers should consider the influence of location and culture and aim to conduct occupant behaviour studies locally.

Another noteworthy point derived from Fig. 2 and Fig. 3 is that pioneer countries in this area have followed two opposite trends. Some of them like the United States and Canada have published one of the first papers in this area in the 1990s and continued working on this subject in the following years till now. In analogy, another pioneer country, Japan, directed the research flow toward other realms. In the next years, other papers also studied Japanese occupants and their thermal behaviour by non-Japanese researchers. This suggests a good method and sets a good example for less developed countries in this field to collaborate with researchers from other countries to study the energy-driven behaviour of their nation to fill the knowledge gap in the research literature and improve management in energy-consuming sectors.

\section{Building Type}

Fig. 4 demonstrates the type and typology of studied cases in the reviewed papers. As shown in the graph, the majority of researches in this field have focused on the occupants of residential buildings. That is because of the longer occupancy period and variation in the energy behaviours of occupants.

The role of occupants in energy consumption is less-regarded in commercial and educational buildings. Energy specialists tend to investigate the energy consumption affected by behaviour mainly in residential buildings (Paper, 2017). Studying occupant-driven energy loads in public types of buildings will have a significant impact on future building design because individual occupants do not have full control of a building's HVAC and lighting systems in these buildings. This can enhance the potential for other forms of interaction with the building to provide comfort conditions (Delzendeh et al., 2017; Martinaitis \& Zavadskas, 2015). As a result, a wider range of variety in occupant behaviour in schools and offices is anticipated, which requires further investigation. Moreover, based on previous BPS (Building Performance Simulation) studies, occupancy default profile may vary a lot from the real behaviour, which makes the simulation results sometimes inaccurate(S. Wang et al., 2017). Consequently, the need for accurate profiles, with an approach to culture and climate is of great importance. O'Brien. Gaetani, et al. conducted an international survey of 274 BPS users and developers and found that occupancy assumption in current energy simulation does not align with the complex behaviour occupants show in buildings and is much simpler than state-of-the-art findings. They also mentioned that simulation users are aware of deficiencies in occupancy profile assumptions and they are open to utilizing more detailed occupancy profiles in their modelling (Brien et al., 2016).

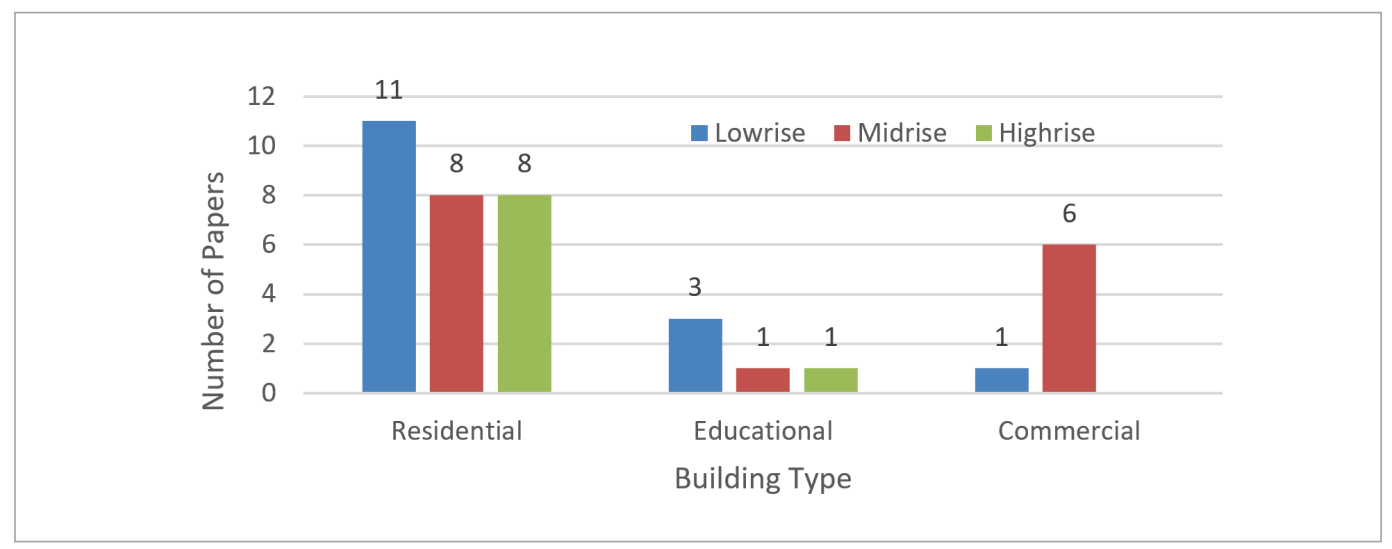

Fig. 4

Studied cases by building type and typology 
In contrast to the majority of papers dealing with occupants and their behaviour in residential and commercial buildings, Schaumann et al. considered simulating occupancy patterns at hospital buildings. As defined by the authors, it is expected that conventional occupant modelling and simulation formalisms may not be suitable in process-driven facilities such as hospitals, airports, train stations, and factories. The authors conducted a new multiagent simulation framework to account for the peculiarities in the modelling of occupancy in such process-driven facilities (Schaumann, Breslav, Goldstein, Khan, \& Kalay, 2017).

Another noteworthy point extracted from the graph is that some specific building typologies are more popular among scientists and others are neglected in reviewed papers. For instance, different typologies of residential buildings are investigated in several studies to answer different research questions, while there was no study evaluating occupant-driven energy load in high-rise commercial buildings.

As the graph demonstrates, among the studied papers, low-rise buildings have drawn more attention in contrast to mid-rise or high-rise buildings. This might be due to the higher frequency and lower level of complexity of the low-rise building. The results show that less than $20 \%$ of studied cases were selected from high-rise buildings. Considering growing attention to high-rise multifunctional buildings in current metropolises, as well as developed construction techniques, it sounds that occupant behaviour in high-rise buildings should be regarded with much interest in the future.

\section{Climate}

Another criterion for categorizing reviewed researches on this subject is based on the climate of the studied cases. Fig. 5 demonstrates the number of studied cases categorized by their climate classes based on Koppen-Geiger climatic classification.

The Köppen-Geiger climate classification divides climates into five classes: A (tropical), B (dry), C (temperate), D (continental), and E (polar). The second letter shows the seasonal precipitation type: $f$ (no dry season), $w$ (winter dry), or s (summer dry). The third letter indicates the warmth of the summer: a (hot summer), b (warm summer), c (cool summer), $d$ (cold summer), h (hot arid) and $\mathrm{K}$ (cold arid). In this climatic system, class names show the most remarkable climatic features of regions in form of three-letters codes.

As shown in the chart below, among reviewed papers, several studies have chosen cases from the same climate, for example, roughly $40 \%$ of investigated cases belong to the climate class of $\mathrm{Cfa}$ (Humid subtropical climates). Cfa climate, which normally is seen on eastern coasts of continents covers, parts of Europe, the United States and China, Brazil, Australia, etc. This climate class has temperate weather, without dry seasons with hot summer. It is mostly humid and a steady rate of precipitation is observed among seasons(Canan, Golasi, Falasca, \& Salata, 2020; Chen \& Chen, 2013; Solutions, Beck, \& Rubel, 2006).

Fig. 5

Frequency of studied climates

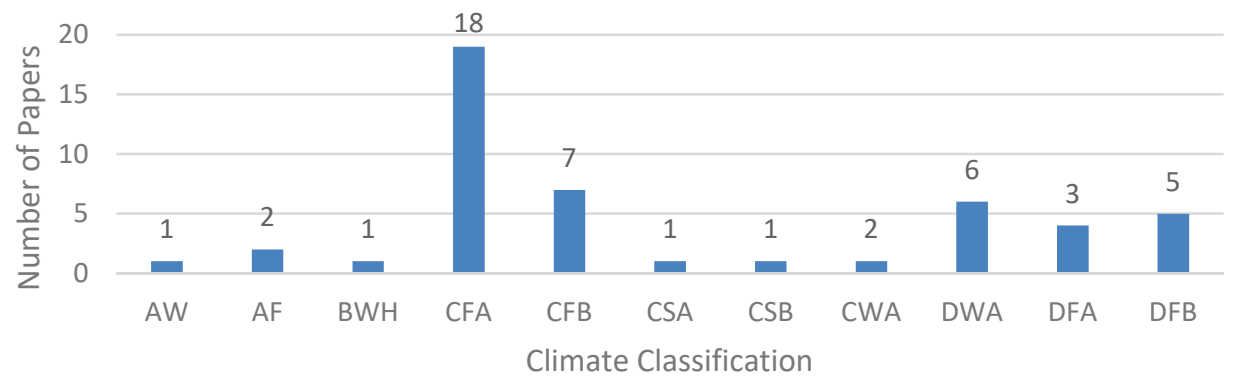


Initially, it might be assumed to be in response to the high population of this area. This is whilst, there are numerous climates with several times more population that have received scant attention such as B (arid), D (continental), some of C (moderate) and A (tropical) (Solutions et al., 2006). The lack of researches in the aforementioned climatic regions, which mostly covers developing countries, again highlights the necessity of investigating the effect of occupant behaviour on building energy consumption in these areas.

\section{Research Type}

In the field of AEC (Architecture, Engineering and Construction), the majority of studies deal with energy consumption or other derived parameters, thus it is anticipated that most researches are conducted with quantitative methods. As the graph shows $75 \%$ percent of papers, report the result of quantitative researches while only $25 \%$ were carried out through qualitative methods.

\section{Qualitative Researches}

To categorize the reviewed papers based on their research methods, there would be two groups of qualitative and quantitative papers. Qualitative researches can be categorized into three classes based on their main objectives and goals as shown in Fig. 6. More than half of the qualitative papers are review papers, which investigate, summarize and outline recent trends in this area of research. In undertaking this paper, we focused more on quantitative researches because of their larger number, more notable achievements, and the researcher's inclination toward them.

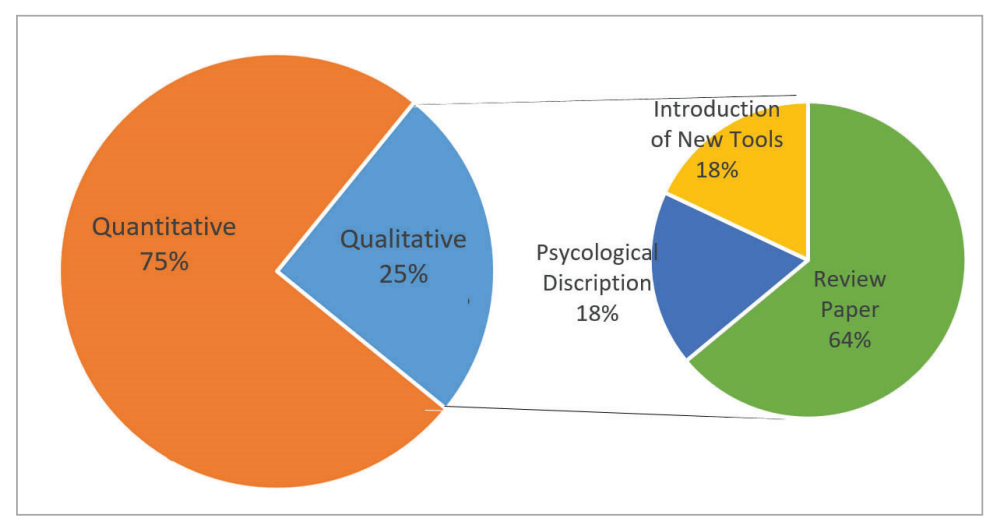

Fig. 6

Research type and major issues

\section{Quantitative Researches}

The majority of papers in this area investigate responses to the research question by quantifying the collection and analysis of data. This type of research is further discussed in this section from two perspectives: the main subject and applied methodology. Similar to qualitative papers, more than half of the quantitative studies focused on energy consumption (65\%). Among all quantitative reviewed papers, the most popular subject that has drawn the researcher's attention is that to what extent and how occupant behaviour can affect energy consumption (Becchio et al., 2016; Burgas, Melendez, \& Colomer, 2014; Deng \& Chen, 2019; Engvall, Lampa, Levin, Wickman, \& Öfverholm, 2014; Leroy \& Yannou, 2018; Norford et al., 1994; Park \& Kim, 2012; Peng, Rysanek, Nagy, \& Schlüter, 2018; Rafsanjani \& Ahn, 2016; Rafsanjani, Ahn, \& Chen, 2018; Santin, 2011; Song et al., 2017; Virote \& Neves-Silva, 2012; Z. Wang, Zhao, Lin, Zhu, \& Ouyang, 2015; S. Wei, Jones, \& de Wilde, 2014; Y. Wei et al., 2019; Xie, Pan, Jia, Xu, \& Huang, 2019; Zhun Yu, Fung, Haghighat, Yoshino, \& Morofsky, 2011; Yu Zhun Jerry, Haghighat, Fung, Morofsky, \& Yoshino, 2011; Yun et al., 2014; Yun \& Kim, 2012). Many studies focused on a single form of energy consumption (either heating, cooling, electricity, DHW (Demanded Hot Water), etc.) and dismissed the impact of occupants on other types of energy consumption. This is in analogy with the fundamentals of building physics in which building is defined as a system with different formats of energy inputs. Hence, for measuring energy consumption, we need to consider all forms of energy consumption. In other words, some of the studies focused on space heating and/or cooling (Engvall et al., 2014; Park \& 
Kim, 2012; Santin, 2011; Song et al., 2017; Z. Wang et al., 2015; S. Wei et al., 2014; Yun \& Kim, 2012; Yun \& Steemers, 2011) or even lighting (Virote \& Neves-Silva, 2012; Yun \& Kim, 2012). They mainly studied how and to what extend occupants' behaviour can affect the specific type of consumption, neglecting that there are some underlying formats of energy that can be affected by occupants at the same time such as energy demand associated with DHW and use of equipment. Therefore, considering only one kind of energy use cannot reflect the performance of a building under the effects of different behaviours. For example, Becchio et al. studied variation in energy use in a midrise apartment in Italy. They measured energy consumption by the heating load, electricity use, and hot water demand. The result showed the difference between the estimated energy consumptions and the monitored data, which revealed a noticeable gap in different forms of energy consumption with a higher amount for real end uses: $+50 \%$ for space heating, $+19 \%$ for DHW, and $+16 \%$ for electricity use. The results not only discovered a greater unprecedented discrepancy between estimated and real use but also revealed that the discrepancy exists in different formats of energy consumption to a different amount. In other words, no single form of energy consumption (space heating, space cooling, lighting, DHW, etc.) can represent the total consumption in a building and none of them can be taken into account solely. Consequently, in order to study occupant behaviour effect on building energy consumption, hot water, space cooling, lighting as well as heating and ventilation should be considered as a package (Becchio et al., 2016).

Fig. 7

Type of research independent variable

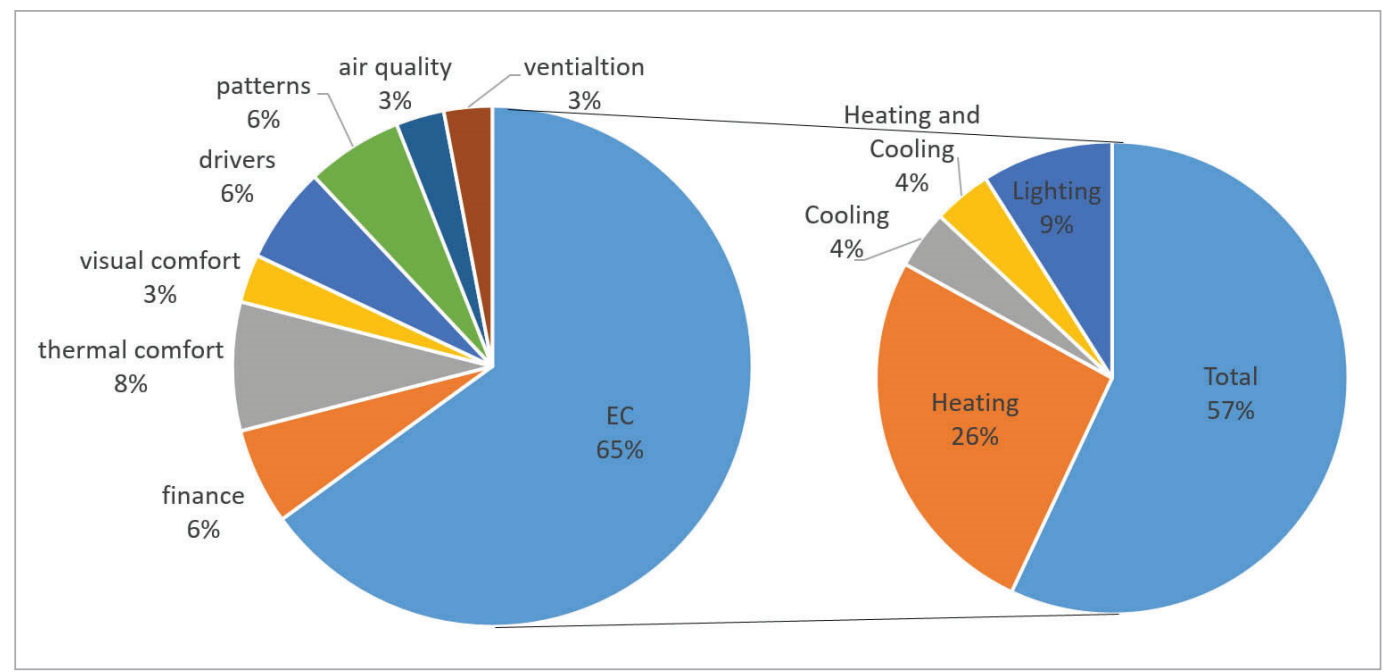

Some of the studied papers addressed the important factor of comfort in studying occupant's energy-driven behaviour to some extends, in form of thermal comfort (Kim et al., 2017; Newsham, 1997; Pellegrino et al., 2016), Visual comfort (Kim et al., 2017; Yun \& Kim, 2012) and air quality (Engvall et al., 2014; Iwashita \& Akasaka, 1997; Kim et al., 2017). Kim et al investigate the optimal occupant behaviour that can simultaneously reduce total energy consumption and improve indoor comfort. They used an energy simulation and particle swarm optimization algorithm in modeling a school in five different cities. They managed to decrease energy consumption by $14.6 \%$ in comparison to the basic model only by optimizing occupant's interaction with the building (Kim et al., 2017). In another study, Pellegrino et al, simulated and validated data about indoor air quality in 18 typical Indian apartments and compared the effect of the low-cost intervention for reducing energy demand. Results revealed that indoor air is more stable and independent from the outdoor thermal condition, than simulation suggests. They mentioned that leaving simulation input to the default schedule for occupancy, internal loads, and natural ventilation can increase inaccuracy significantly. They also showed that the use of night natural ventilation has a pivotal effect on the thermal performance of buildings in the city of Kolkata (Pellegrino et al., 2016). 
Researchers also paid attention to the impact of occupant behaviour on the economic side of the building sector (Mohamed, Al-Habaibeh, Abdo, \& Elabar, 2015; S. Wang et al., 2017; Yun \& Steemers, 2011). In a study, Ahemd et al. evaluate the effect of domestic energy consumption and occupants' behaviour pattern on the national scale energy consumption in Libya and how this could affect the peak demand, capacity and energy budget. The result of their study reveals that energy-conscious behaviour coupled with utilizing more efficient appliances and lighting systems could significantly save energy up to a large power station of 2 GW (Mohamed et al., 2015).

Determining behaviour deriver (Alam et al., 2017; Hong et al., 2015) and occupancy pattern (Yun \& Kim, 2012) for enhancing the accuracy of simulation results was also among the topics in the reviewed papers with less frequency. Bedir and Kara in their paper analyzed electrical appliance use in the Dutch housing stock and identified behavioural patterns and profiles of electricity consumption. The result of their study can lead to more accurate results of simulation studies for reporting electricity needs (Bedir \& Kara, 2017). This was an example of a limited number of papers focusing on occupancy profile because the majority of researches regard the dependant variable with a psychological approach including biological, psychological, socioeconomic, sociodemographic, and contextual factors, which is out of the scope of this review.

\section{Research Variables}

The second most popular issue among the reviewed papers was conducted aiming to configure near-real occupancy scenarios. Only $11 \%$ of the reviewed studies deal with the behaviour patterns or occupancy profile in response to the urgent demand for accurate occupancy patterns utilized in simulation tools (Bedir \& Kara, 2017; Z. Yu et al., 2015; Yun \& Kim, 2012).

In terms of the parameters influencing occupants' energy behaviours, comfort conditions (Thermal, visual, and air quality) have been taken into account in $20 \%$ of papers. Considering the fact that indoor environmental quality (IEQ) factors may have a contradictory impact on different forms of comfort conditions, almost in all research, occupants' behaviour was studied assuming only one form of

\begin{tabular}{|c|c|c|c|}
\hline Parameter & Variable & number & Percentage \\
\hline \multirow{5}{*}{ ENERGY CONSUMPTION } & Total load & 15 & $43 \%$ \\
\hline & Space heating \& cooling load & 1 & $2.8 \%$ \\
\hline & Only Space cooling load & 1 & $2.8 \%$ \\
\hline & Only Space heating load & 5 & $14 \%$ \\
\hline & overall & 22 & $63 \%$ \\
\hline \multirow{3}{*}{ Thermal Comfort } & $P P D$ & 2 & $6 \%$ \\
\hline & $\mathrm{CIDH}$ & 1 & $2.8 \%$ \\
\hline & overall & 3 & $8.5 \%$ \\
\hline Visual comfort & Lux & 2 & $6 \%$ \\
\hline \multirow{4}{*}{ Occupant } & Pattern & 2 & $6 \%$ \\
\hline & Profile & 2 & $6 \%$ \\
\hline & Framework & 1 & $2.8 \%$ \\
\hline & overall & 4 & $11 \%$ \\
\hline Finance & & 2 & $6 \%$ \\
\hline \multirow{3}{*}{ Air quality } & $\mathrm{CO}_{2}$ & 1 & $2.8 \%$ \\
\hline & Ventilation rate and air temperature & 1 & $2.8 \%$ \\
\hline & overall & 2 & $6 \%$ \\
\hline
\end{tabular}

Table 1

Dependent Variable in Studied Papers 
comfort condition. This has been either IAQ (Indoor Air Quality) (Iwashita \& Akasaka, 1997; Kim et al., 2017), thermal (Kim et al., 2017; Newsham, 1997; Pellegrino et al., 2016), or visual comfort(Kim et al., 2017; Yun \& Kim, 2012). Researchers measured the CIDH (Comfort Indoor Degree Hours) or PPD (Predicted Percentage of Dissatisfied) index as indicators for comfort conditions. It is important to keep in mind that occupant behaviour is a dynamic phenomenon and building occupants change their behaviour to provide general comfort conditions, therefore there is a crucial gap in this area and need occupant energy-driven behaviour to be addressed under complete comfort conditions.

In the bottom, $6 \%$ of the quantitative papers addressed financial issues (Mohamed et al., 2015; S. Wang et al., 2017) and almost the same amount investigate air quality (measuring the $\mathrm{CO}_{2}$ concentration, ventilation rate, etc.).

Table 2 reports a quantitative summary of the investigated independent variables. Results show that the effect of Occupant behaviour on visual comfort in buildings has not been investigated sufficiently. Considering visual conditions as an important part of overall comfort in future studies can fill this gap. This can be conducted by measuring the illuminance level, as an important, measurable, and comprehensive variable to assess visual comfort and functionality of a space.

\section{Methods for Data Collection}

\section{Experimental Methods}

To cluster the applied methodology, three major methods and combinations of them can summarize how researchers collect data in quantitative studies:

Simulation Studies, Experiments, and Questionnaires.

As shown in Fig. 8 the majority of the studies in this realm are conducted by experimental studies. The most implemented field measurement methods are pre and post-occupancy surveys as well as occupant monitoring using sensors or observation, and questionnaires. Experiment has been the sole method of the study or in some cases has been backed up with simulation(Becchio et al., 2016; Norford et al., 1994; Rafsanjani \& Ahn, 2016; Xie et al., 2019; Yun et al., 2014) or data analysis(Pellegrino et al., 2016). A few studies used a hybrid method for data collection and benefit from all three methods to evaluate their research hypothesis precisely(Song et al., 2017; Z. Wang et al., 2015). It is also observed that researchers regard simulations and survey evenly in this area. Besides quantitative methods, researchers also used descriptive and analytical methods as well although they are applied in fewer studies(Alam et al., 2017; Mohamed et al., 2015; Yun \& Steemers, 2011).

In a comprehensive study, Gilani and O'Brien provide a complete description of in-situ monitoring methods, technologies, and challenges to study occupant's behaviour. They highlighted the

Fig. 8

Diagram of data collecting method frequency in quantitative researches.

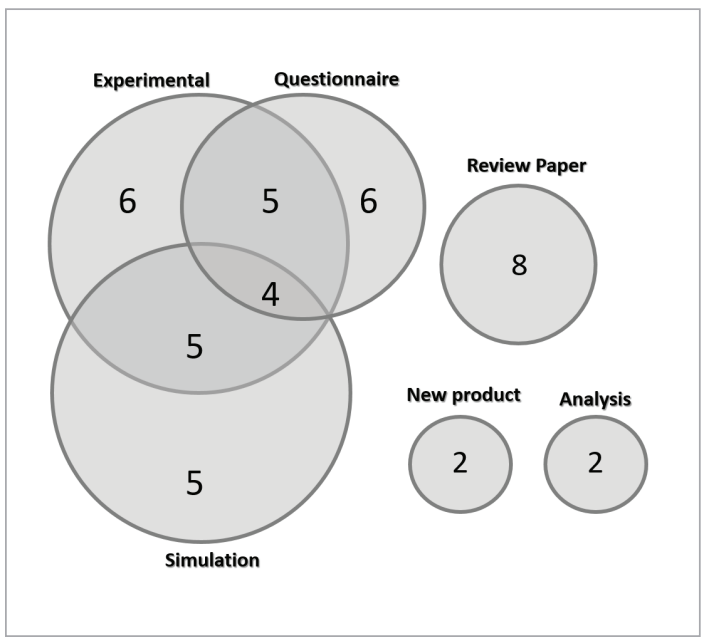
advantages as the reality of the obtained data, the potential for large sample size and long-term data collection at relatively low cost, and future sensing technologies. They also find the shortcomings of this method of study in the issues with stand-alone and connected sensors, impediments to achieving a large sample size, the Hawthorne effect, and the errors of self-reporting. They also emphasized the benefits, afforded by mixed research methods, such as adding surveys to traditional sensor-based monitoring campaigns. Next, the authors discuss some of the major methodological challenges including (Gilani et al., 2017). 


\section{Simulation}

Simulation is the second most popular method in quantifying the effect of occupant behaviour on building energy consumption. In recent years with the advent of new software and analysis engines, there are numerous options ahead of researchers for making a simulation model. Accuracy and valid results, ease of application, and model-making process are the most important criteria to choose software in simulation studies. Fig. 9 summarizes the application of software in behaviour studies. As shown in the graph EnergyPlus (Pellegrino et al., 2016; Xie et al., 2019; Yun et al., 2014)and DeST (Rafsanjani \& Ahn, 2016; Z. Wang et al., 2015) are widely used to simulate the energy-driven behaviour of occupants.

Feng et al. in their paper discuss an important challenge in BPS. They determined an adequate number of simulations for statistically representative probabilistic building performance in commercial buildings. In their research, they focused on the appropriate repetition in occupant behaviour simulation. By comparing the results of space cooling consumption with several input time intervals, they recommended 10 repetitions as appropriate simulation repetition and temporal discretization in building simulation considering occupant behaviour (Feng et al., 2016).

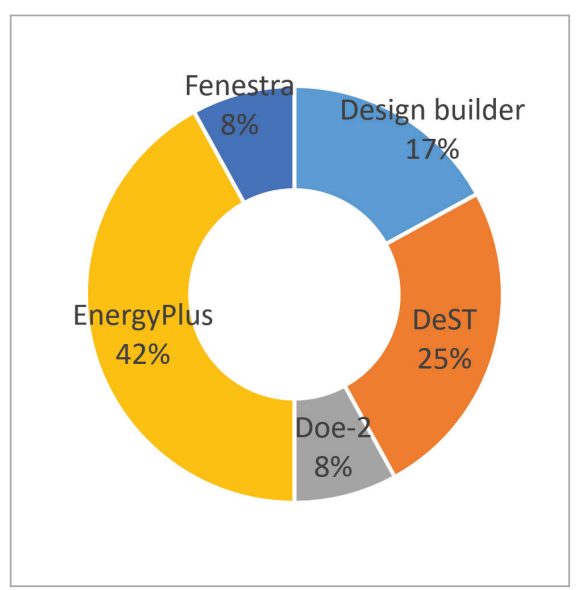

Fig. 9

The most popular software

\section{Questionnaire}

Fig. 10 shows the number of studied cases in an individual paper according to the research method. As the graph shows, the highest numbers of monitored cases in research, are observed in survey-based papers. Researchers prefer questionnaires for collecting data when investigating behaviour on large scale is needed. Among the reviewed papers in the current study, questionnaires with an average of 372 have the most cases. However far more questionnaires are needed in calculation-based studies. Ahmed et al. collected 429 valid questionnaires to evaluate the effect of domestic energy consumption behaviour on overall energy consumption in Libya and the way it affects the peak demand, capacity, future trends, and national energy budget (Mohamed et al., 2015). Yun and Steemers in their research investigated the significance of behavioural, physical, and socio-economic parameters on cooling demand in residential buildings through 2718 buildings in Columbia state, USA(Yun \& Steemers, 2011). In researches using simulation for data collection, a considerably lower number of studied cases is observed. The decrease in the number

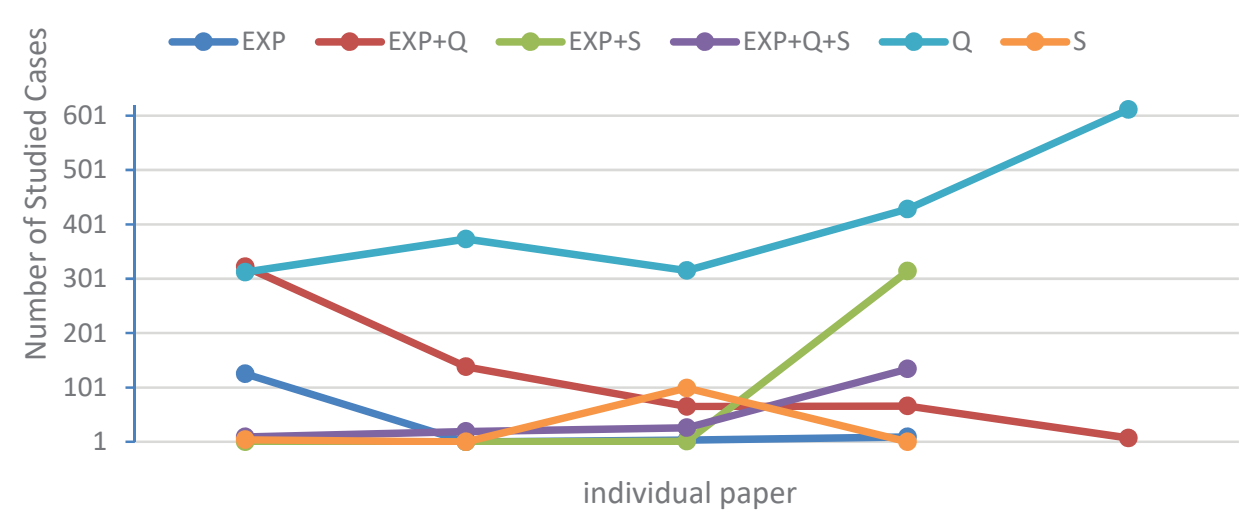

\section{Fig 10}

Number of studied cases in a single research according to data collection method $(\mathrm{EXP}=$ Experimental methods, $\mathrm{Q}=$ Questionnaire, $\mathrm{S}=$ Simulation and model making) 
of cases in the simulation-based or assisted method is due to the time-consuming process of simulation, which is still a challenge to apply white-model simulations.

In some studies, however, the researcher decides to evaluate, support, or boost data from the questionnaires, with an experimental method, such as field measurement. In these cases due to time consuming and difficult process of in-situ measurement, the number of studied cases drops remarkably. Experimental methods are also applied as the data collection method in research, especially in cases that accuracy and thorough analysis of the mechanism of energy consumption was of great importance rather than figuring the pattern in vast samples.

Simulation as the third method of data collection was also used extensively, mostly in studies with a limited domain of research. Among the reviewed papers, a simulation was taken into account in projects with a limited number of cases ("bp-stats-review-2018-all-data," n.d.; Kim et al., 2017; Newsham, 1997; Pellegrino et al., 2016; Xie et al., 2019). This method is not suggested in largescale studies due to modeling difficulties, calculation inaccuracies and limited computing power of current devices and software. On an urban scale normal statistical method was applied (Alam et al., 2017; Mohamed et al., 2015). In a number of studies, three methods of data gathering were applied in order to understand the subject deeper (Deng \& Chen, 2019; Song et al., 2017; Z. Wang et al., 2015; C. Yu, Du, \& Pan, 2019). This type of hybrid data-gathering method is yet rare to find.

As mentioned in section 2 of this paper, the impact of occupant's behaviour on building consumption is a growing research interest. Numerous studies have investigated the direct or indirect impact of occupants and their behaviour on the energy consumption in different buildings with the ultimate goal of reducing the total energy use or mitigating the performance gap between the predicted and actual energy consumption of buildings. This paper reviewed the most recent related publications related to occupant energy behaviour in buildings to identify different scientific approaches to studying the complex behaviour of occupants and how it affect total energy consumption in buildings. To reach this, reviewed papers were categorized in terms of different perspectives such as building type, building typology, building morphology, dependent variables, research type, data gathering method, number of cases, climate, and location distribution.

\section{The evolutionary trend of research}

The number of projects regarding occupant-driven building energy is truly increasing through the studied period especially after 2011. Among the studies period, there were years with a significantly fewer number of published papers. To determine the trends and hot topics, the authors decided to conduct a qualitative method with the tool of interviews. The aim of the qualitative section of the study is first to help gathering information on independent variables, scope, goals, and other characteristics of the researches in gap years and secondly, to validate the reliability of the trends derived from papers. As mentioned previously, selected participants in the interviews are experts and certified specialists in simulation and building energy studies. The interview continued to reach repetitive results, which shows the saturation. The result of the interview analysis was in convergence with the review study. It reveals that respectively comfort conditions (Fabi, Andersen, Corgnati, \& Olesen, 2012; Hong et al., 2015; Rafsanjani \& Ahn, 2016; Salcido, Raheem, \& Issa, 2016; Z. Wang et al., 2015; S. Wei et al., 2014), payback period, and financial aspect of energy conservation strategies (Juodis, Jaraminiene, \& Dudkiewicz, 2009; Nicol \& Humphreys, 2002; Sorrell, Dimitropoulos, \& Sommerville, 2009) are the hottest research topics in the 2000s. in Fig. 11 (underlined items are added from a qualitative method.)

Fig. 11 shows the evolutionary trend of the research community in this field and summarizes the most remarkable milestones and achievements per year. As the figure shows, the trend of scientific studies commenced proving the gap between anticipated and real consumption and estimating the amount of this gap roughly. In the next level, researchers focused on the leading rea- 


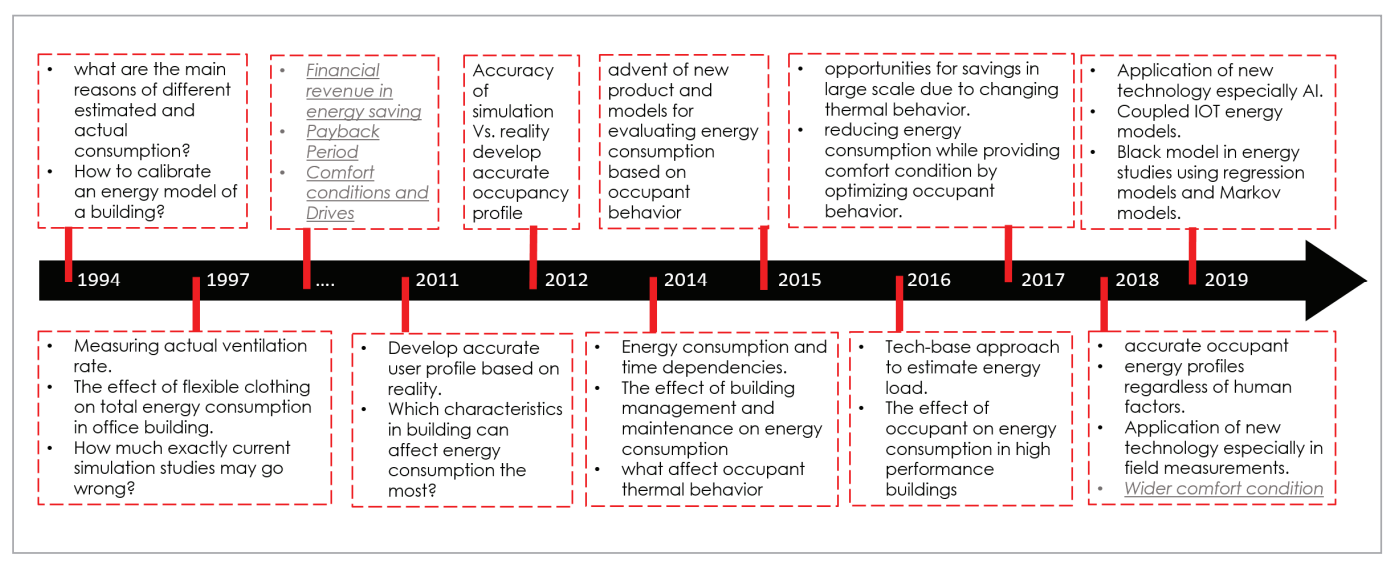

Fig. 11

Timeline of Highlights: Occupant Behaviour in Energy Simulation Studies

sons for this gap, most consider them as single-external-nonrelated factors (such as Clo-factor, Met factor, interactions with building, etc.). In the second decade, more researches with diverse approaches, are observed investigating the side effects of this discrepancy and a further investigation of the reasons. For instance, some researches have been conducted with an economic approach dealing with the financial break of sustainable building projects due to inaccuracy of energy estimation and payback period (Sorrell et al., 2009) as well as other researches investigating difficulties in modelling behaviour due to psychological reasons (Indraganti \& Rao, 2010; Juodis et al., 2009; Leroy \& Yannou, 2018).

As the research in this area continued, more projects aimed to mitigate this gap, not considering the origins and essence of influential factors, but the effects and consequences. In the last section of the studied period, which is still being pursued, researchers have found out that as many influencing factors as possible should be addressed simultaneously. They managed to tie them up under the occupants' comfort (Deng \& Chen, 2019; Engvall et al., 2014; Kim et al., 2017; Pellegrino et al., 2016). In recent publications, researchers have focused on the relation of comfort conditions and related energy consumption by new methods and utilizing advanced technologies (Hong et al., 2015; Marique, De Meester, De Herde, \& Reiter, 2014; Rafsanjani et al., 2018). This recent trend has succeeded to mitigate the gap more than ever, therefore it is still a popular research trend in recent years.

The investigations of this study that result in determining the scientific trend in this area are totally in line with other reviews although it adds more insights to them. O'Brien et al. in a paper investigate the most recent achievements in occupant behaviour research. They categorize research stages into phases of data collection, modelling and simulation and explain fundamentals through literature. They emphasize the remaining questions to be addressed in future studies. They speculate that occupant modeling and simulation are still in the primitive phase. They refer to Gartner's Hype Cycle and evaluate occupant researches in the early stages (Gilani et al., 2017).

\section{Modelling Occupant Behaviour}

According to the reviewed papers, it is concluded that one of the main reasons for energy simulation inaccuracy is the inaccurate assumption for occupant behaviour. In other words, occupants' active and passive energy behaviours (including window opening, use of solar shading and blinds, adjusting HVAC set points, use of hot water, etc.) are not considered completely and correctly in current energy analysis tools. Thus, there is a noticeable demand to improve the results of energy modeling by reflecting the behaviour of occupants in simulation studies. This can be fulfilled by defining more accurate and near-real occupancy profiles in energy simulation tools, however, it could not be done without facing several challenges; The main challenge in this part is the complexity and dynamic nature of occupants' energy behaviour, which is influenced by various 
Table 2. Summary of data from quantitative reviewed papers

\begin{tabular}{|c|c|c|c|c|c|c|c|c|c|c|}
\hline & AUTHOR & Year & $\begin{array}{l}\text { Dependent } \\
\text { Variable }\end{array}$ & $\begin{array}{l}\text { Data Gather- } \\
\text { ing Method }\end{array}$ & Climate* $^{*}$ & Location & Building type & $\begin{array}{l}\text { Building } \\
\text { Typology }\end{array}$ & $\begin{array}{l}\text { Building } \\
\text { morphology }\end{array}$ & $\begin{array}{l}\text { Number of } \\
\text { studied cases } \\
\text { in the paper }\end{array}$ \\
\hline 1 & $\begin{array}{l}\text { Z. Deng Q. Chen } \\
\text { (Deng \& Chen, 2019) }\end{array}$ & 2019 & $\mathrm{EC}$ & $\begin{array}{l}\text { Questionnaire } \\
\& \text { Simulation } \\
\& \text { Experiment }\end{array}$ & Dfa & West Lafayette & Commercial & Mid-rise & Detached & 20 \\
\hline 2 & $\begin{array}{l}\text { C. Yu et al. (C. Yu et al., } \\
\text { 2019) }\end{array}$ & 2019 & $\mathrm{EC}$ & $\begin{array}{l}\text { Questionnaire } \\
\& \text { Simulation } \\
\& \text { Experiment }\end{array}$ & Cwa & Hong Kong & Residential & High-rise & Detached & 988 \\
\hline 3 & $\begin{array}{l}\text { J. Xiea et al. (Xie et al., } \\
\text { 2019) }\end{array}$ & 2019 & $\mathrm{EC}$ & $\begin{array}{l}\text { Experimental } \\
\& \text { Simulation }\end{array}$ & Cwa & Shanghai & Residential & High-rise & Detached & 315 \\
\hline 4 & $\begin{array}{l}\text { J. Rouleau et al. } \\
\text { (Rouleau, Gosselin, \& } \\
\text { Blanchet, 2019) }\end{array}$ & 2019 & & $\begin{array}{l}\text { Experimental } \\
\& \text { Simulation }\end{array}$ & Dfb & Quebec City & Residential & High-rise & NA & 40 \\
\hline 6 & $\begin{array}{l}\text { M. Oritz p. Bluyssen } \\
\text { (Ortiz \& Bluyssen, } \\
\text { 2018) }\end{array}$ & 2018 & & Questionnaire & $\mathrm{Cfb}$ & Amsterdam & residential & Low-rise & $\begin{array}{l}\text { Semi- } \\
\text { Detached }\end{array}$ & 316 \\
\hline 7 & $\begin{array}{l}\text { Y. Leroy, B. Yannou } \\
\text { (Leroy \& Yannou, } \\
\text { 2018) }\end{array}$ & 2018 & EC & Questionnaire & $\begin{array}{l}\text { Cfb } \\
\text { (Majority) }\end{array}$ & France & Residential & & & $\begin{array}{l}\text { National } \\
\text { Scale }\end{array}$ \\
\hline 8 & $\begin{array}{l}\text { Y. Peng et al. (Peng et } \\
\text { al., 2018) }\end{array}$ & 2018 & EC & Experimental & $\mathrm{Cfb}$ & Switzerland & Commercial & Mid-rise & $\begin{array}{l}\text { Semi- } \\
\text { Detached }\end{array}$ & 11 \\
\hline 9 & $\begin{array}{l}\text { L. Songa et al.(Song } \\
\text { et al., 2017) }\end{array}$ & 2017 & $\mathrm{EC}^{* *}$ & $\begin{array}{l}\text { Questionnaire } \\
\& \text { Simulation } \\
\& \text { Experiment }\end{array}$ & Cfa & Shanghai & Residential & High-rise & Detached & 10 \\
\hline 13 & $\begin{array}{l}\text { C. Becchio et } \\
\text { al.(Becchio et al., } \\
\text { 2016) }\end{array}$ & 2016 & EC & $\begin{array}{l}\text { Experiment \& } \\
\text { Simulation }\end{array}$ & $\begin{array}{l}\text { Cfa } \\
\text { Csa }\end{array}$ & Turin & Residential & Mid-rise & Detached & 1 \\
\hline 14 & $\begin{array}{l}\text { M. Ouf, M. Issaa, P. } \\
\text { Merkelb(Ouf et al., } \\
\text { 2016) }\end{array}$ & 2016 & EC & Experiment & Dfb & Manitoba & Educational & Low-rise & Detached & 126 \\
\hline 15 & $\begin{array}{l}\text { H. Nabizadeh- } \\
\text { Rafsanjani, A. } \\
\text { Changbum- } \\
\text { Ahna(Rafsanjani \& } \\
\text { Ahn, 2016) }\end{array}$ & 2016 & EC & $\begin{array}{l}\text { Experiment \& } \\
\text { Simulation }\end{array}$ & Dfa & Nebraska & Commercial & Mid-rise & Detached & \\
\hline 16 & $\begin{array}{l}\text { M. Pellegrino, } \\
\text { M. Simonetti, G. } \\
\text { Chiesa(Pellegrino et } \\
\text { al., 2016) }\end{array}$ & 2015 & $\begin{array}{l}\text { Thermal } \\
\text { Comfort }\end{array}$ & Simulation & Aw & Kolkata & Residential & Mid-rise & Attached & 1 \\
\hline 17 & $\begin{array}{l}\text { Z. Yu et al. (Z. Yu et al., } \\
\text { 2015) }\end{array}$ & 2015 & $\mathrm{EC}$ & Experiment & Cfa & $\begin{array}{l}\text { Honzyo, } \\
\text { Tohoku } \\
\text { Japan }\end{array}$ & Residential & Low-rise & Detached & 1 \\
\hline
\end{tabular}




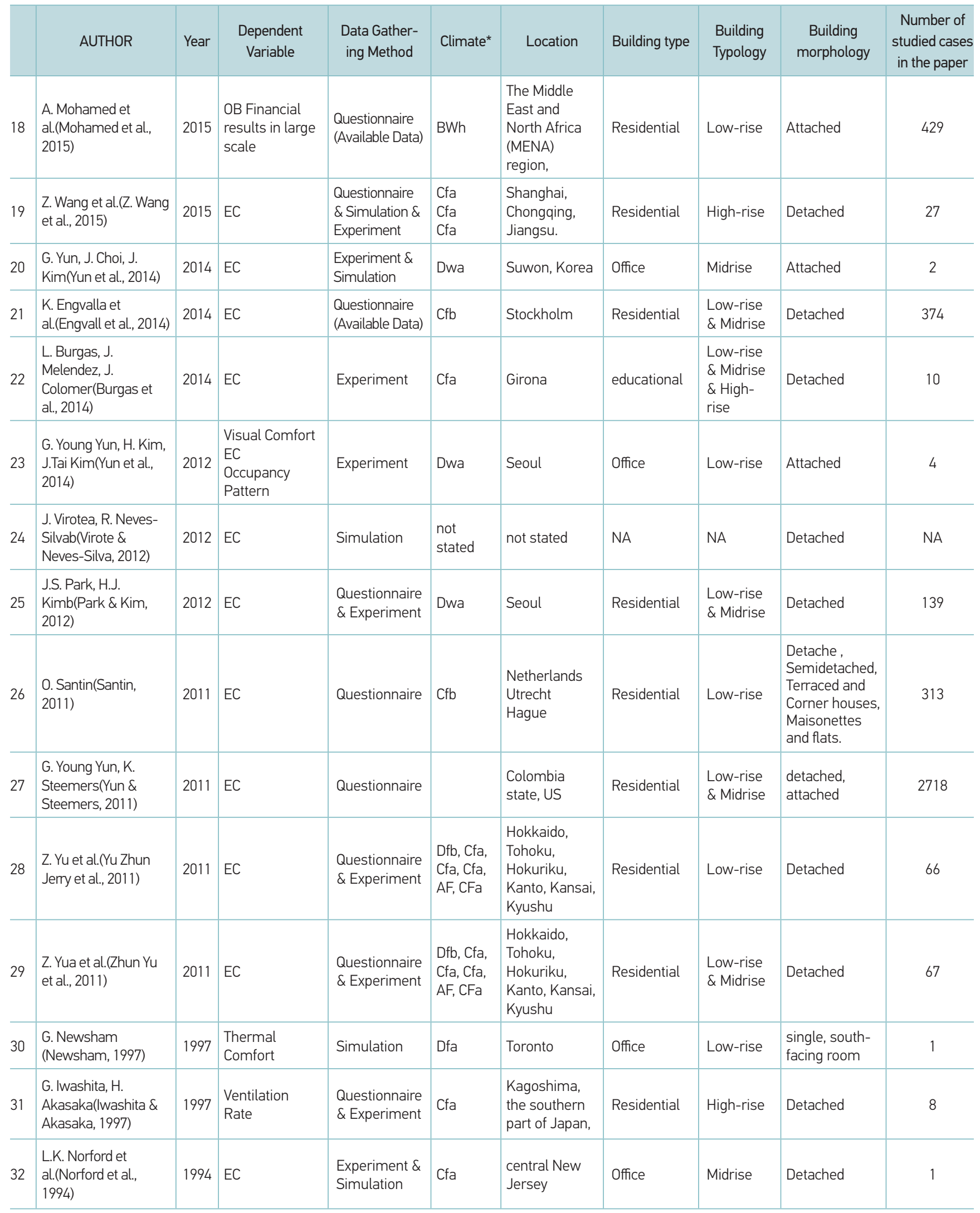

EC - Energy Consumption OB - Occupant Behaviour * based on Koppen-Geiger climatic classification 
psychological, climatic and contextual factors. Therefore, occupants' interaction with the building needs to be studied in a multidisciplinary approach to incorporate driving factors from sociological, psychological, economics, engineering, and design perspectives to obtain a much more accurate occupancy profile. This way, real-time interactions with the building can be correctly reflected and help in generating more realistic assumptions in building energy prediction.

An alarming point observed in the reviewed papers is that researchers need to pay attention to the level of simplification in modelling real conditions. Occupants change behaviour to provide comfort, often regardless of energy. The sensible and crucial factor for the occupant is total comfort. That is in analogy with some researches in which only one format of energy consumption or one form of comfort condition is addressed. This is due to the complexity in comfort calculation and is an attempt to simplify the condition. In some iterations, the researcher may manage to reduce energy consumption under simplified comfort conditions by changing the behaviour but has exerted a negative impact on other types of comfort. For instance, interactions with windows, shades, and blinds can help to provide thermal comfort and reducing consumption while simultaneously may hurt visual comfort and overall shows a negative effect on comfort condition. It is highly recommended to investigate the differences made by occupant behaviour on energy consumption in near-real conditions. To address this flaw in more developed researches is needed. Measuring and monitoring IEQ can be a good way to evaluate comfort conditions while behaviour changes.

Accordingly, researchers and scholars in this field need to pay more attention to comfort conditions and apply more accurate modelling of the real environment. Moreover, there is a strong need to bring scientific achievement into comfort simulation and apply more advanced calculations and simulation tools in this regard.

In this paper, a comprehensive literature review was conducted by elaborating a theoretical framework to study the potential impact of occupant behaviour on energy consumption in buildings from all over the world. This literature review aims to look into remarkable achievements and knowledge gap in this field of research, as well as investigating significant trends in the last three decades as a required step for predicting future trends in this topic.

The result of this review showed that the occupant behaviour has a big impact on energy consumption and the comfort condition, which has not been reflected accurately in simulation studies due to its dynamic and complex nature.

The analysis of the literature highlight that a comprehensive approach to identifying the effect of occupants' behaviour in real comfort condition has not yet been conducted. Most studies focus on either determining occupant's simplified interaction with the building or monitoring energy consumption under one form of comfort (either thermal, visual, etc.) which is not an extraction of real condition in the built environment. Neglecting the fact that different forms of comfort are interwoven and inseparable in real conditions, has lead to inaccuracy in simulation results. It is also ignored that indoor environmental factors may have a contradictory effect on different forms of comfort. In this sense, authors suggest conducting similar research considering real comfort conditions via experiments and in-situ studies and using $\mathrm{CIDH}$ based assessment.

The results also revealed that a significant number of existing studies focused on evaluating energy-sensitive behaviour in specific regions and cultures from developed countries. Currently, modelers in regions with a limited research background in this area, tend to generalize the results of available studies, which results in wrong assumptions, and inaccuracy of simulation results. Considering socio-cultural forces in forming occupant behaviour, there is a strong need to conduct more research in less regarded regions. Also with the advent of new technology in simulating occupant behaviour, such as smart learning agents and meta-models, it is anticipated that this field of research will be revolutionized with accurate energy prediction and real modelling of behaviour and interactions with building in near future. 
Alam, M. M., Bao, H., Zou, P. X. W., \& Sanjayan, J. (2017). Behaviour Change of Building Users and Energy Consumption BT - Reference Module in Earth Systems and Environmental Sciences. Encyclopedia of Sustainable Technologies (Vol. 2). Elsevier. https://doi.org/10.1016/B978-0-12-4095489.10193-9

Becchio, C., Bello, C., Corgnati, S. P., \& Ingaramo, L. (2016). Influence of Occupant Behaviour Lifestyle on an Italian Social Housing. Energy Procedia, 101, 1034-1041. https://doi.org/10.1016/j.egypro.2016.11.131

Bedir, M., \& Kara, E. C. (2017). Behavioural patterns and profiles of electricity consumption in dutch dwellings. Energy and Buildings, 150, 339-352. https://doi.org/10.1016/j.enbuild.2017.06.015

Bemanian, M., \& Torabi, M. (2019). شعر ىسانشزاب

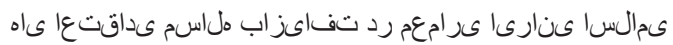
[Determining Theoretical Origins of Recycling in Iranian-Islamic Architecture; with Grounded Theory Approach]. NAqshe-Jahan, 9(3), 167-175. Retrieved from https:// bsnt.modares.ac.ir/browse.php?a_id=35337\&slc_ lang=en\&sid=2\&printcase $=1 \& \mathrm{hbnr}=1 \& \mathrm{hmb}=1$

Brien, W. O., Gaetani, I., Gilani, S., Carlucci, S., Hensen, J., Brien, W. O., ... Carlucci, S. (2016). International survey on current occupant modelling approaches in building performance simulation. Journal of Building Performance Simulation, 0(0), 1-19. https://doi.org/1 0.1080/19401493.2016.1243731

Burgas, L., Melendez, J., \& Colomer, J. (2014). Principal component analysis for monitoring electrical consumption of academic buildings. Energy Procedia, 62, 555-564. https://doi.org/10.1016/j.egypro.2014.12.417

Canan, F., Golasi, I., Falasca, S., \& Salata, F. (2020). Science of the Total Environment Outdoor thermal perception and comfort conditions in the Köppen-Geiger climate category BSk. One-year fi eld survey and measurement campaign in Konya , Turkey, 738. https://doi.org/10.1016/j.scitotenv.2020.140295

Chen, D., \& Chen, H. W. (2013). Using the Köppen classification to quantify climate variation and change : An example for 1901 - 2010, 6, 69-79. https://doi. org/10.1016/j.envdev.2013.03.007

Delzendeh, E., Wu, S., Lee, A., \& Zhou, Y. (2017). The impact of occupants' behaviours on building energy analysis: A research review. Renewable and Sustainable Energy Reviews, 80(May), 1061-1071. https:// doi.org/10.1016/j.rser.2017.05.264

Deng, Z., \& Chen, Q. (2019). PT US CR. Energy \& Buildings. https://doi.org/10.1016/j.enbuild.2019.06.015

Engvall, K., Lampa, E., Levin, P., Wickman, P., \& Öfver- holm, E. (2014). Interaction between building design, management, household and individual factors in relation to energy use for space heating in apartment buildings. Energy and Buildings, 81, 457-465. https:// doi.org/10.1016/j.enbuild.2014.06.051

Fabi, V., Andersen, R. V., Corgnati, S., \& Olesen, B. W. (2012). Occupants' window opening behaviour: A literature review of factors influencing occupant behaviour and models. Building and Environment, 58, 188-198. https://doi.org/10.1016/j.buildenv.2012.07.009

Feng, X., Yan, D., \& Wang, C. (2016). On the simulation repetition and temporal discretization of stochastic occupant behaviour models in building performance simulation. Journal of Building Performance Simulation, 0(0), 1-13. https://doi.org/10.1080/19401493 .2016 .1236838

Gilani, S., Brien, W. O., Gilani, S., \& Brien, W. O. (2017). Review of current methods, opportunities, and challenges for in-situ monitoring to support occupant modelling in office spaces occupant modelling in office spaces, 1493(July). https://doi.org/10.1080/194 01493.2016 .1255258

Hong, T., D'Oca, S., Taylor-Lange, S. C., Turner, W. J. N., Chen, Y., \& Corgnati, S. P. (2015). An ontology to represent energy-related occupant behaviour in buildings. Part II: Implementation of the DNAS framework using an XML schema. Building and Environment, 94, 196-205. https://doi.org/10.1016/j. buildenv.2015.08.006

Indraganti, M., \& Rao, K. D. (2010). Effect of age, gender , economic group and tenure on thermal comfort : A field study in residential buildings in hot and dry climate with seasonal variations, 42, 273-281. https://doi.org/10.1016/j.enbuild.2009.09.003

Iwashita, G., \& Akasaka, H. (1997). The effects of human behaviour on natural ventilation rate and indoor air environment in summer \{ltextemdash\} a field study in southern Japan. Energy and Buildings, 25, 195-205. https://doi.org/10.1016/S03787788(96)00994-2

Juodis, E., Jaraminiene, E., \& Dudkiewicz, E. (2009). Inherent variability of heat consumption in residential buildings, 41, 1188-1194. https://doi.org/10.1016/j. enbuild.2009.06.007

Kim, J., Hong, T., Jeong, J., Lee, M., Lee, M., Jeong, K., ... Jeong, J. (2017). Establishment of an optimal occupant behaviour considering the energy consumption and indoor environmental quality by region. Applied Energy, 204, 1431-1443. https://doi. org/10.1016/j.apenergy.2017.05.017

Leroy, Y., \& Yannou, B. (2018). Computers in Industry An activity-based modelling framework for quantifying occupants ' energy consumption in residential

\section{References}


buildings. Computers in Industry, 103, 1-13. https:// doi.org/10.1016/j.compind.2018.08.009

Marique, A. F., De Meester, T., De Herde, A., \& Reiter, S. (2014). An online interactive tool to assess energy consumption in residential buildings and for daily mobility. Energy and Buildings, 78, 50-58. https:// doi.org/10.1016/j.enbuild.2014.04.016

Martinaitis, V., \& Zavadskas, E. K. (2015). Importance of occupancy information when simulating energy demand of energy efficient house : A case study, 101, 64-75. https://doi.org/10.1016/j.enbuild.2015.04.031

Mohamed, A. M. A., Al-Habaibeh, A., Abdo, H., \& Elabar, S. (2015). Towards exporting renewable energy from MENA region to Europe: An investigation into domestic energy use and householders' energy behaviour in Libya. Applied Energy, 146, 247-262. https://doi.org/10.1016/j.apenergy.2015.02.008

Newsham, G. R. (1997). Clothing as a thermal comfort moderator and the effect on energy consumption. Energy and Buildings, 26(3), 283-291. https:// doi.org/10.1016/S0378-7788(97)00009-1

Nicol, J. F., \& Humphreys, M. A. (2002). Adaptive thermal comfort and sustainable thermal standards for buildings, 34, 563-572. https://doi.org/10.1016/ S0378-7788(02)00006-3

Norford, L. K., Socolow, R. H., Hsieh, E. S., \& Spadaro, G. V. (1994). Two-to-one discrepancy between measured and predicted performance of a "low-energy" office building: insights from a reconciliation based on the DOE-2 model. Energy and Buildings, 21(2), 121131. https://doi.org/10.1016/0378-7788(94)90005-1

Ortiz, M. A., \& Bluyssen, P. M. (2018). Proof-of-concept of a questionnaire to understand occupants ' comfort and energy behaviours : First results on home occupant archetypes. Building and Environment, 134(November 2017), 47-58. https://doi. org/10.1016/j.buildenv.2018.02.030

Ouf, M., Issa, M., \& Merkel, P. (2016). Analysis of real-time electricity consumption in Canadian school buildings. Energy and Buildings, 128, 530-539. https://doi.org/10.1016/j.enbuild.2016.07.022

Paper, C. (2017). A conceptual framework to simulate building occupancy using crowd modelling techniques for energy analysis, (October).

Park, J. S., \& Kim, H. J. (2012). A field study of occupant behaviour and energy consumption in apartments with mechanical ventilation. Energy and Buildings, 50, 19-25. https://doi.org/10.1016/j.enbuild.2012.03.015

Pellegrino, M., Simonetti, M., \& Chiesa, G. (2016). Reducing thermal discomfort and energy consumption of Indian residential buildings: Model validation by in-field measurements and simulation of low-cost interventions. Energy and Buildings, 113, 145-158. https://doi. org/10.1016/j.enbuild.2015.12.015

Peng, Y., Rysanek, A., Nagy, Z., \& Schlüter, A. (2018). Using machine learning techniques for occupancy-prediction-based cooling control in o ffi ce buildings. Applied Energy, 211(November 2017), 1343-1358. https://doi.org/10.1016/j.apenergy.2017.12.002

Rafsanjani, H. N., \& Ahn, C. (2016). Linking Building Energy-Load Variations with Occupants' Energy-Use Behaviours in Commercial Buildings: Non-Intrusive Occupant Load Monitoring (NIOLM). Procedia Engineering, 145, 532-539. https://doi.org/10.1016/j. proeng.2016.04.041

Rafsanjani, H. N., Ahn, C. R., \& Chen, J. (2018). PT US CR. Energy \& Buildings. https://doi.org/10.1016/j. enbuild.2018.05.007

Rouleau, J., Gosselin, L., \& Blanchet, P. (2019). Robustness of energy consumption and comfort in high-performance residential building with respect to occupant behaviour. Energy, 188, 115978. https:// doi.org/10.1016/j.energy.2019.115978

Salcido, J. C., Raheem, A. A., \& Issa, R. R. A. (2016). From simulation to monitoring: Evaluating the potential of mixed-mode ventilation (MMV) systems for integrating natural ventilation in office buildings through a comprehensive literature review. Energy and Buildings, 127, 1008-1018. https://doi. org/10.1016/j.enbuild.2016.06.054

Santin, O. G. (2011). Behavioural patterns and user profiles related to energy consumption for heating. Energy and Buildings, 43(10), 2662-2672. https://doi. org/10.1016/j.enbuild.2011.06.024

Schaumann, D., Breslav, S., Goldstein, R., Khan, A., \& Kalay, Y. E. (2017). Simulating the Behaviour of Building Occupants using Multi-agent Narratives : A Preliminary Study in a Generic Hospital Ward, Building Simulation Procedia, 2017, San Fransisco, p 175-182.

Solutions, R. M., Beck, C., \& Rubel, F. (2006). World Map of the Köppen-Geiger climate classification updated, (May). https://doi.org/10.1127/09412948/2006/0130

Song, L., Zhou, X., Zhang, J., Zheng, S., \& Yan, S. (2017). Air-conditioning Usage Pattern and Energy Consumption for Residential Space Heating in Shanghai China. Procedia Engineering, 205, 31383145. https://doi.org/10.1016/j.proeng.2017.10.139

Sorrell, S., Dimitropoulos, J., \& Sommerville, M. (2009). Empirical estimates of the direct rebound effect: A review, 37, 1356-1371. https://doi. org/10.1016/j.enpol.2008.11.026

Virote, J., \& Neves-Silva, R. (2012). Stochastic models for building energy prediction based on occupant be- 
haviour assessment. Energy and Buildings, 53, 183193. https://doi.org/10.1016/j.enbuild.2012.06.001

Wang, S., Kim, A. A., \& Johnson, E. M. (2017). Understanding the deterministic and probabilistic business cases for occupant based plug load management strategies in commercial office buildings. Applied Energy, 191, 398-413. https://doi.org/10.1016/j.apenergy.2017.01.082

Wang, Z., Zhao, Z., Lin, B., Zhu, Y., \& Ouyang, Q. (2015). Residential heating energy consumption modeling through a bottom-up approach for China's Hot Summer-Cold Winter climatic region. Energy and Buildings, 109, 65-74. https://doi. org/10.1016/j.enbuild.2015.09.057

Wei, S., Jones, R., \& de Wilde, P. (2014). Driving factors for occupant-controlled space heating in residential buildings. Energy and Buildings, 70, 36-44. https://doi.org/10.1016/j.enbuild.2013.11.001

Wei, Y., Yu, H., Pan, S., Xia, L., Xie, J., Wang, X., ... Li, Q. (2019). Comparison of di ff erent window behaviour modeling approaches during transition season in Beijing, China. Building and Environment, 157(March), 1-15. https://doi.org/10.1016/j. buildenv.2019.04.040

Xie, J., Pan, Y., Jia, W., Xu, L., \& Huang, Z. (2019). Energy-consumption simulation of a distributed air-conditioning system integrated with occupant behaviour. Applied Energy, 256(4800), 113914. https://doi.org/10.1016/j.apenergy.2019.113914

Yu, C., Du, J., \& Pan, W. (2019). Energy \& Buildings Improving accuracy in building energy simulation via evaluating occupant behaviours : A case study

\section{MAHSA TORABI}

\section{Researcher}

HAL (High-Performance Architecture)

\section{Main research area}

Energy simulation modeling, Life cycle assessment, Artificial intelligence in Architecture Occupant behaviour

\section{Address}

Department of Architecture, Faculty of Art and Architecture, Tarbiat Modares University, Al-Ahmad, Tehran Iran.

Tel. +989125146905

E-mail: mst.torabi@modares.ac.ir in Hong Kong, 202. https://doi.org/10.1016/j.enbuild.2019.109373

Yu, Z., Fung, B. C. M., Haghighat, F., Yoshino, H., \& Morofsky, E. (2011). A systematic procedure to study the influence of occupant behaviour on building energy consumption. Energy and Buildings, 43(6), 1409-1417. https://doi.org/10.1016/j.enbuild.2011.02.002

Yu, Z., Li, J., Li, H. Q., Han, J., \& Zhang, G. Q. (2015). A Novel Methodology for Identifying Associations and Correlations Between Household Appliance Behaviour in Residential Buildings. Energy Procedia, 78, 591-596. https://doi.org/10.1016/j.egypro.2015.11.024

Yu Zhun Jerry, Z. J., Haghighat, F., Fung, B. C. M., Morofsky, E., \& Yoshino, H. (2011). A methodology for identifying and improving occupant behaviour in residential buildings. Energy, 36(11), 6596-6608. https://doi.org/10.1016/j.energy.2011.09.002

Yun, G. Y., Choi, J., \& Kim, J. T. (2014). Energy performance of direct expansion air handling unit in office buildings. Energy and Buildings, 77, 425-431. https://doi.org/10.1016/j.enbuild.2014.03.039

Yun, G. Y., \& Kim, H. (2012). Effects of occupancy and lighting use patterns on lighting energy consumption. Energy and Buildings, 46, 152-158. https://doi. org/10.1016/j.enbuild.2011.10.034

Yun, G. Y., \& Steemers, K. (2011). Behavioural, physical and socio-economic factors in household cooling energy consumption. Applied Energy, 88(6), 2191-2200. https://doi.org/10.1016/j.apenergy.2011.01.010 